\title{
Investigation of calcium phosphate (CaP) tribofilms from commercial automatic transmission fluids (ATFs) and their correlation with antishudder performance
} \author{
Shaohui LI \\ Dalian Lubricating Oil Research \& Development Institute, PetroChina, Dalian 116032, China \\ Received: 10 October 2018 / Revised: 26 December 2018 / Accepted: 30 May 2019 \\ (C) The author(s) 2019.
}

Zechao DI ${ }^{*}$, Jingjing XU, Yang LIU, Yu JIANG, Dongsheng HUANG, Haitao CUI, Zhongguo LIU, Zhiyu ZHAO,

\begin{abstract}
The friction properties of wet clutches are highly dependent on the surface tribofilms formed by automatic transmission fluids (ATFs). Here, four commercial ATFs were evaluated with a disc-on-disc tribometer to study tribofilm formation on steel surfaces and the effects of tribofilms on the friction properties. The chemical composition, stoichiometry, structure, and thickness of the tribofilms were investigated by scanning electron microscopy (SEM), energy dispersive X-ray spectrometry (EDX), secondary ion mass spectrometry (SIMS), and $\mathrm{X}$-ray photoelectron spectroscopy (XPS). Calcium phosphate (CaP) tribofilms form on the friction surface with all ATFs, which contributes to their antishudder characteristics. The thickness and surface coverage of $\mathrm{CaP}$ tribofilms are positively correlated with their antishudder properties.
\end{abstract}

Keywords: tribofilm; commercial ATF; antishudder; hydroxyapatite

\section{Introduction}

Wet clutches are used in automatic transmissions to transmit torque. The primary component of a wet clutch is the tribological paper and steel discs immersed in the ATF. During engagement of the wet clutch, the paper disc (static) and steel disc (rotating) are pushed together by force, and then friction between the discs eliminates the speed difference, and the two discs rotate at the same speed to reach a state of lock up. Thus, power is transmitted from an input to an output shaft [1]. This friction between surfaces is a crucial feature of automatic transmission performance. However, uncontrolled friction often causes shudder. For instance, when the dependence of the kinetic friction coefficient on the relative velocity ( $\mu-v$ curve) is negative, steady sliding at the equilibrium point becomes unstable, and the instability generates shudder [2]. Stick-slip is another type of shudder that results from the discontinuity between static and kinetic friction; stick-slip can arise when the static friction is higher than the dynamic friction $[3,4]$. The tendencies of a wet clutch to experience both stick-slip and shudder are usually characterized by the $\mu-v$ curve. A positive slope of the $\mu-v$ curve is beneficial if stick-slip and shudder are to be avoided.

Tribofilms play a key role in controlling friction in boundary and mixed lubrications [5, 6]. Some lubricant additives, such as antiwear (AW), friction modifier (FM), and detergent, are known to chemically interact with metallic surfaces to form tribofilms, and the friction characteristics are affected by the tribofilms [7-13]. Tribofilms protect the substrate from excessive wear, reduce/increase the friction coefficient, and maintain good anti-seizure performance [14, 15]. Antishudder performance of wet clutches can be modulated by FMs and other additives in ATFs [16-18]. Our previous study found that a CaP tribofilm formed by FM and

* Corresponding author: Zechao DI, E-mail: dizechao_rhy@petrochina.com.cn 
detergent affected friction characteristics [19, 20]. Zhao et al. $[8,21]$ investigated the chemical composition of tribofilms containing $\mathrm{P}$ and $\mathrm{Ca}$ on the steel friction plate of the clutch. Tohyama et al. $[16,17]$ found that the combination of Ca-containing FM and P-containing detergent provides good antishudder performance. Fitima et al. [18] also reported that Ca-containing detergents and FMs affected antishudder properties. However, these abovementioned studies are based on laboratory formulations; there are few studies on commercial ATFs and their actual performance.

Many analytical techniques are used to analyze tribofilms. Rydel et al. [6] studied the dependence between the morphology of the tribofilm and the microstructure of the underlying material by atomic force microscopy (AFM). Tipton et al. [22] characterized changes in tribofilm chemistry by scanning auger microscopy (SAM). However, SAM is not suitable for detecting tribofilms with a thickness of more than $200 \mathrm{~nm}$. Auger electron spectroscopy (AES) was used for surface elemental mapping of tribofilms by Qu et al. [23]. In this study, XPS depth analysis is used, in which the chemical composition of tribofilm is determined down to a depth of approximately $900 \mathrm{~nm}$. Moreover, the 2-D imaging of secondary ion mass spectrometry (SIMS) is a very effective way to observe the distribution state of elements on different layers in the tribofilm [24]. In addition, SIMS 2-D mapping can accurately measure the ion concentration in the micro-region, which serves as a primary method for comparing the thickness and distribution intensity of tribofilms.

Most of the studies discussed above used labformulated ATFs; however, many formulations cannot be applied in practice because of the poor compatibility of additives and other negative effects for ATFs. This study uses four commercial ATFs. SEM, EDX, SIMS, and XPS are used to comprehensively characterize the composition of tribofilms. Tribological testing is carried out to study the relationship between a tribofilm and its antishudder characteristics. Although the formulations are different, the antishudder properties can be primarily attributed to the CaP tribofilms formed by reactions among additives. The combination of XPS depth analysis and SIMS 2-D imaging confirms that thicker and more densely distributed tribofilm is beneficial to antishudder performance. These results provide deeper insights into the actual working conditions of ATFs.

\section{Experimental}

\subsection{Tribological testing}

A Wazau tribometer (Wazau Co., Ltd., Germany), a miniature version of the LVFA [25], was used to evaluate the $\mu-v$ characteristics in this study (Fig. 1). In a $50 \mathrm{ml}$ oil tank, a paper disc (BorgWarner 6100) is rotated on a static steel disc. The contact pressure, relative speed between friction couple, and the temperature of the oil were set according to the test procedure. The friction coefficient at various speeds, loads, and temperatures were recorded. The test procedure was carried out according to JASO M349 for LVFA [19, 20, 25]. The tribological testing for each condition was done in triplicate.

\subsection{Test oil}

Oils A, B, C, and D from four well-known ATF companies were purchased for this study. These oils were chosen based on their applicability and generality with high market share. The characteristics of the four ATFs are shown in Table 1. Oils A, B, and C passed the JASO standard to satisfy the antishudder requirement, while ATF-D only met the DEXRON III standard without antishudder characteristics.

ATFs were tested in the Wazau test rig to evaluate their friction performance. The $\mu-v$ curves and the steel discs from Wazau tests were analyzed.

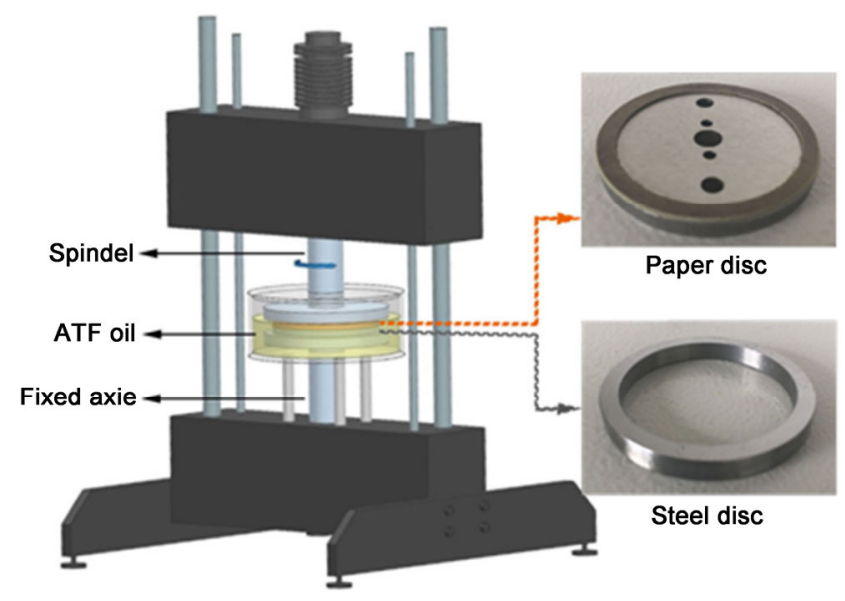

Fig. 1 Wazau test rig. 
Table 1 Characteristics of ATFs A, B, C, and D.

\begin{tabular}{|c|c|c|c|c|c|}
\hline \multirow{2}{*}{ Company } & Oil A & Oil B & Oil C & Oil D & \multirow{2}{*}{$\begin{array}{c}\text { Test } \\
\text { method }\end{array}$} \\
\hline & A, USA & $\mathrm{B}, \mathrm{UK}$ & $\mathrm{C}$, USA & $\mathrm{D}$, China & \\
\hline Kinematic viscosity $\left(100^{\circ} \mathrm{C}\right)\left(\mathrm{mm}^{2} \cdot \mathrm{s}^{-1}\right)$ & 6.177 & 6.143 & 6.006 & 7.916 & ASTM D445 \\
\hline Viscosity index & 154 & 150 & 151 & 202 & ASTM D2270 \\
\hline Acid number $\left(\mathrm{mg} \mathrm{KOH} \cdot \mathrm{g}^{-1}\right)$ & 3.29 & 1.28 & 1.69 & 1.16 & ASTM D664 \\
\hline Density $\left(20^{\circ} \mathrm{C}\right)\left(\mathrm{kg} / \mathrm{m}^{3}\right)$ & 845 & 844 & 845 & 846 & ASTM D1298 \\
\hline $\mathrm{Ba}\left(\mathrm{mg} /\left(\mathrm{kg} / \mathrm{m}^{3}\right)\right)$ & $<0.1$ & $<0.1$ & 2.8 & - & ASTMD5185 \\
\hline $\mathrm{B}\left(\mathrm{mg} /\left(\mathrm{kg} / \mathrm{m}^{3}\right)\right)$ & 129 & 68.9 & 106 & 164 & ASTMD5185 \\
\hline $\mathrm{Ca}\left(\mathrm{mg} /\left(\mathrm{kg} / \mathrm{m}^{3}\right)\right)$ & 48 & 121 & 174 & 58.6 & ASTMD5185 \\
\hline $\operatorname{Mg}\left(\mathrm{mg} /\left(\mathrm{kg} / \mathrm{m}^{3}\right)\right)$ & $<0.1$ & 0.35 & 0.56 & - & ASTMD5185 \\
\hline $\mathrm{P}\left(\mathrm{mg} /\left(\mathrm{kg} / \mathrm{m}^{3}\right)\right)$ & 289 & 196 & 501 & 297 & ASTMD5185 \\
\hline $\mathrm{Si}\left(\mathrm{mg} /\left(\mathrm{kg} / \mathrm{m}^{3}\right)\right)$ & $<0.7$ & 5.3 & 3.9 & $<0.2$ & ASTMD5185 \\
\hline $\mathrm{Zn}\left(\mathrm{mg} /\left(\mathrm{kg} / \mathrm{m}^{3}\right)\right)$ & $<0.4$ & $<0.3$ & 2.73 & $<0.6$ & ASTMD5185 \\
\hline Satisfied standards & JASO $1 \mathrm{~A}$ & JASO 1A & JASO 1A & GM DEXRON III & - \\
\hline
\end{tabular}

\subsection{Surface analysis}

Surface analysis was carried out to determine the topography and chemical composition of tribofilms. The steel friction surfaces were analyzed by scanning electron microscopy (SEM, Philips XL-30 ${ }^{\mathrm{TM}}$ ), energy dispersive $\mathrm{X}$-ray spectrometry (EDX, Philips XL-30 ${ }^{\mathrm{TM}}$ ) and X-ray photoelectron spectroscopy (XPS, Thermo Electron ESCA 250).

ToF-SIMS analysis was carried out (TOF SIMS V, ION-TOF GmbH, Muenster, Germany) to study the element distribution of the post-test steel surface tribofilm. Analysis was performed using a pulsed $\mathrm{Bi}^{+}$ ion high energy beam of $30 \mathrm{KeV}$ with a current of $1 \mathrm{pA}$ on a $500 \mu \mathrm{m} \times 500 \mu \mathrm{m}$ scanned area. A 2-D SIMS image was generated by scanning the $\mathrm{Bi}_{3}{ }^{+}$primary ion beam over the sample $(50 \mu \mathrm{m} \times 50 \mu \mathrm{m}, 256$ pixels $\times$ 256 pixels) 50 times using Surface Lab6 software (ION·TOF, Münster, Germany).

In the XPS detection, an X-ray spot size of approximately $500 \mu \mathrm{m}$ was chosen. Peak detail spectra were obtained at pass energy of $50 \mathrm{eV}$. The hydrocarbon $\mathrm{C} 1 \mathrm{~s}$ peak at $284.6 \mathrm{eV}$ was used as the binding energy reference. Depth profiles were performed with $3 \mathrm{kV}$ Ar ion sputtering. A sputter time of $10 \mathrm{~s}$ roughly corresponds to a depth of $1 \mathrm{~nm}$, with a systematic uncertainty of $50 \%$. By successively sputtering off the top layers, the chemical composition of tribofilm was determined down to a depth of approximately $900 \mathrm{~nm}$.

\section{Results and discussion}

\subsection{Friction results}

The durability of the antishudder property is an important criterion to evaluate the overall performance of an ATF formulation [20]. Figure 2 shows $\mu-v$ curve $\left(40{ }^{\circ} \mathrm{C}\right)$ results of the four ATFs by the Wazau endurance-aging test. The sign of $\mathrm{d} \mu / \mathrm{d} v$ at $v=0.3$ and $0.9 \mathrm{~m} / \mathrm{s}$ on the $\mu-v$ curves shown in Table 2 is the judgment of antishudder property (JASO M349: 2001-5.1).

ATF-A shows a relatively good positive slope for its $\mu-v$ curve $(\mathrm{d} \mu / \mathrm{d} v(0.3 \mathrm{~m} / \mathrm{s})>0.00, \mathrm{~d} \mu / \mathrm{dv}(0.9 \mathrm{~m} / \mathrm{s})>$ 0.00 ) at 0 and $24 \mathrm{~h}$. The slope of $48 \mathrm{~h} \mu-v$ curve in the speed region of $0.4-1.0 \mathrm{~m} / \mathrm{s}$ becomes slightly negative $(\mathrm{d} \mu / \mathrm{d} v(0.9 \mathrm{~m} / \mathrm{s})<0.00)$. Then, the $72 \mathrm{~h}$ result shows a negative friction curve slope $(\mathrm{d} \mu / \mathrm{d} v(0.3 \mathrm{~m} / \mathrm{s})<0.00$, $\mathrm{d} \mu / \mathrm{d} v(0.9 \mathrm{~m} / \mathrm{s})<0.00)$, which means that the antishudder characteristic deteriorates between 48 and $72 \mathrm{~h}$.

ATF-B exhibits the best antishudder durability among the four oils. It maintains $\mathrm{d} \mu / \mathrm{d} v(0.3 \mathrm{~m} / \mathrm{s})$ and $\mathrm{d} \mu / \mathrm{d} v(0.9 \mathrm{~m} / \mathrm{s})$ values above 0.0 for longer than $144 \mathrm{~h}$. The $\mu-v$ curves from 0 to $144 \mathrm{~h}$ are all quite positive, as shown in Fig. 2(b). The slope of the $168 \mathrm{~h} \mu$ - $v$ curve, which shows a positive slope from the beginning, becomes negative when speed exceeds $0.3 \mathrm{~m} / \mathrm{s}$. The $192 \mathrm{~h} \mu-v$ curve shows a steep negative slope for low speed. 

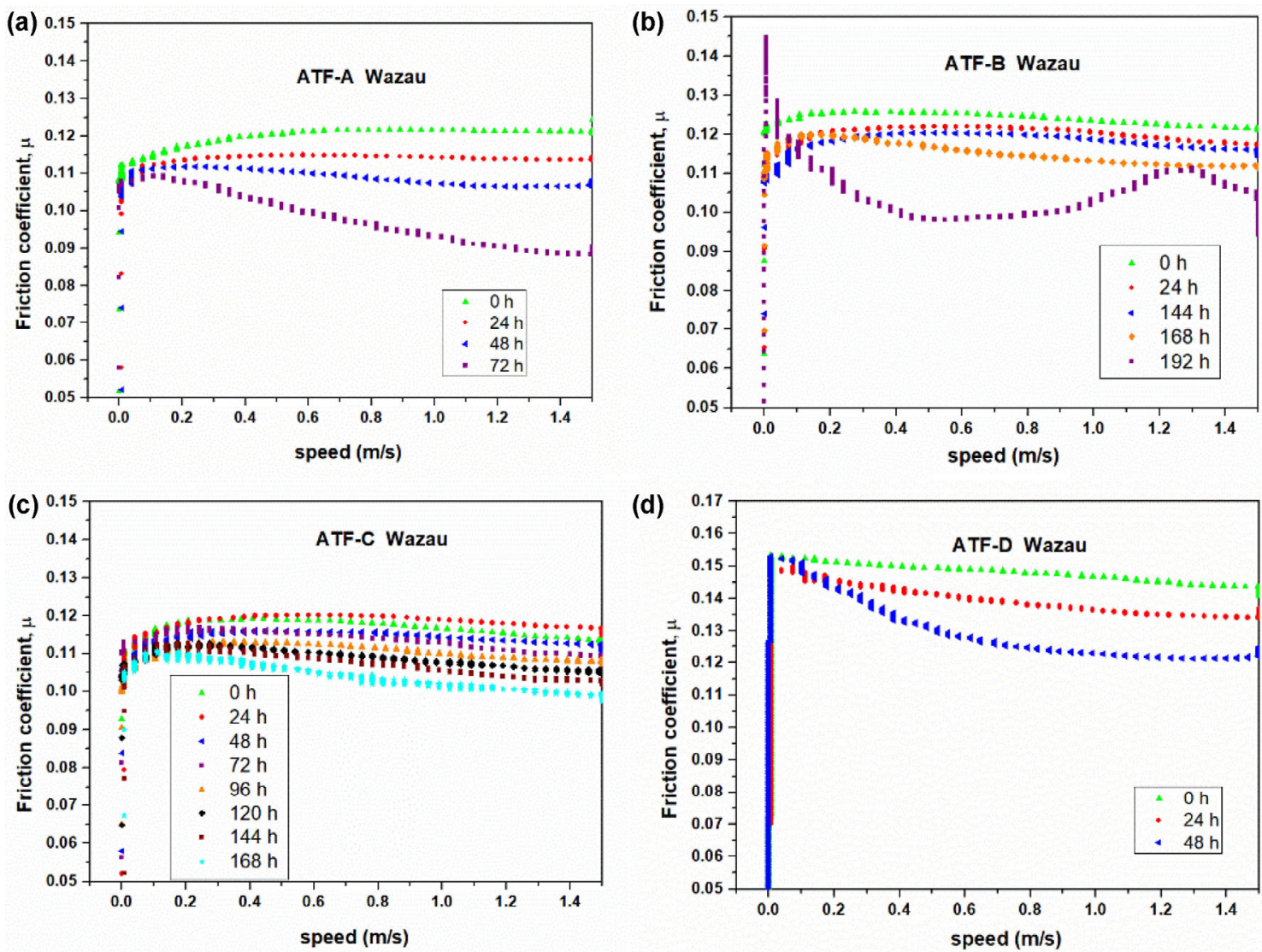

Fig. $2 \mu-v$ curves after endurance test for ATFs A, B, C, and D.

Table $2 \mathrm{~d} \mu / \mathrm{d} v$ at 0.3 and $0.9 \mathrm{~m} / \mathrm{s}$.

\begin{tabular}{ccccccccccc}
\hline $\mathrm{d} \mu / \mathrm{d} \nu$ & $v(\mathrm{~m} / \mathrm{s})$ & $0 \mathrm{~h}$ & $24 \mathrm{~h}$ & $48 \mathrm{~h}$ & $72 \mathrm{~h}$ & $96 \mathrm{~h}$ & $120 \mathrm{~h}$ & $144 \mathrm{~h}$ & $168 \mathrm{~h}$ & $192 \mathrm{~h}$ \\
\hline \multirow{2}{*}{ ATF-A } & 0.3 & + & + & + & - & - & - & - & - & - \\
& 0.9 & + & + & - & - & - & - & - & - & - \\
\hline \multirow{2}{*}{ ATF-B } & 0.3 & + & + & + & + & + & + & + & + \\
& 0.9 & + & + & + & + & + & + & + & - & - \\
\hline \multirow{2}{*}{ ATF-C } & 0.3 & + & + & + & + & + & - & - & - & - \\
& 0.9 & - & - & - & - & - & - & - & - \\
\hline \multirow{2}{*}{ ATF-D } & 0.3 & - & - & - & - & - & - & - & - & - \\
& 0.9 & - & - & - & - & - & - & - & - \\
\hline
\end{tabular}

The $\mathrm{d} \mu / \mathrm{d} v(0.3 \mathrm{~m} / \mathrm{s})$ values for ATF-C remain above 0.0 until approximately $96 \mathrm{~h}$, but the degree of the positive slope for the low-speed region becomes eased with aging. The $\mu-v$ characteristics in the high-speed region have a negative slope after $24 \mathrm{~h}$, and the negative slope value increases slowly with aging.

The slope of the $\mu-v$ curve for ATF-D appears negative from 0 hours (Fig. 2(d)). With increasing durability time, the degree of negative slope is rapidly deepened. Throughout the entire aging test, all the $\mathrm{d} \mu / \mathrm{d} v(0.3$ and $0.9 \mathrm{~m} / \mathrm{s})$ values are less than 0 .

The antishudder durability of ATFs A and C is 48 and $96 \mathrm{~h}$, respectively, which is less than that of ATF-B (168 h), while ATF-D has no antishudder property.

After $24 \mathrm{~h}$ of durability testing, ATFs A, B, and C possess antishudder characteristics. The slopes of the $\mu-v$ curves at $24 \mathrm{~h}$ for ATFs A, B, and C are positive while that of ATF-D is negative. The analyses of the steel surface after $24 \mathrm{~h}$ durability testing are presented in Section 3.2 below. 


\subsection{Steel surfaces analysis}

\subsubsection{SEM and EDX}

The $24 \mathrm{~h}$ post-test steel disc surfaces for the four oils are shown in Figs. 3(a), 4(a), 5(a), and 6(a). SEM pictures of steel discs at the time of complete disappearance of antishudder characteristics (72, 192, and $120 \mathrm{~h}$ for
ATFs A, B, and C, respectively) are shown in Figs. 3(b), $4(b)$, and $5(b)$. Figure $6(b)$ is the SEM image of steel disc after $48 \mathrm{~h}$ of endurance-aging for ATF-D.

Black tribofilms are detected on the surface of the four ATFs (Figs. 3-6). Several points in the tribofilms are selected for EDX analysis, as shown in Fig. 7. The tribofilms of ATFs A, B, C, and D mainly contain Ca,
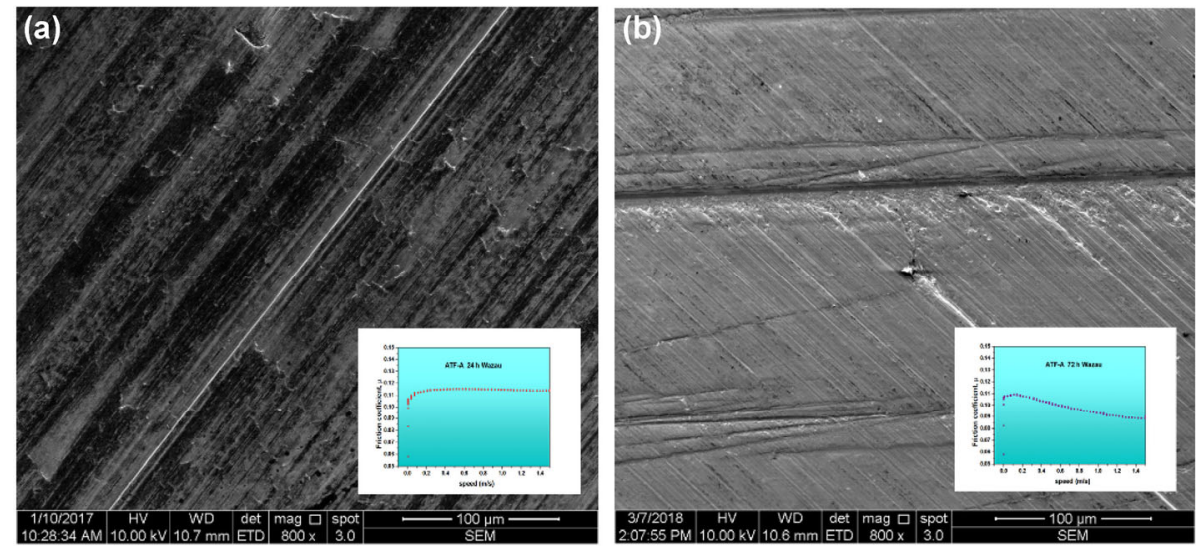

Fig. 3 SEM images of post-test steel disc surfaces after (a) $24 \mathrm{~h}$ and (b) $72 \mathrm{~h} \mathrm{Wazau}$ durability tests for ATF-A.
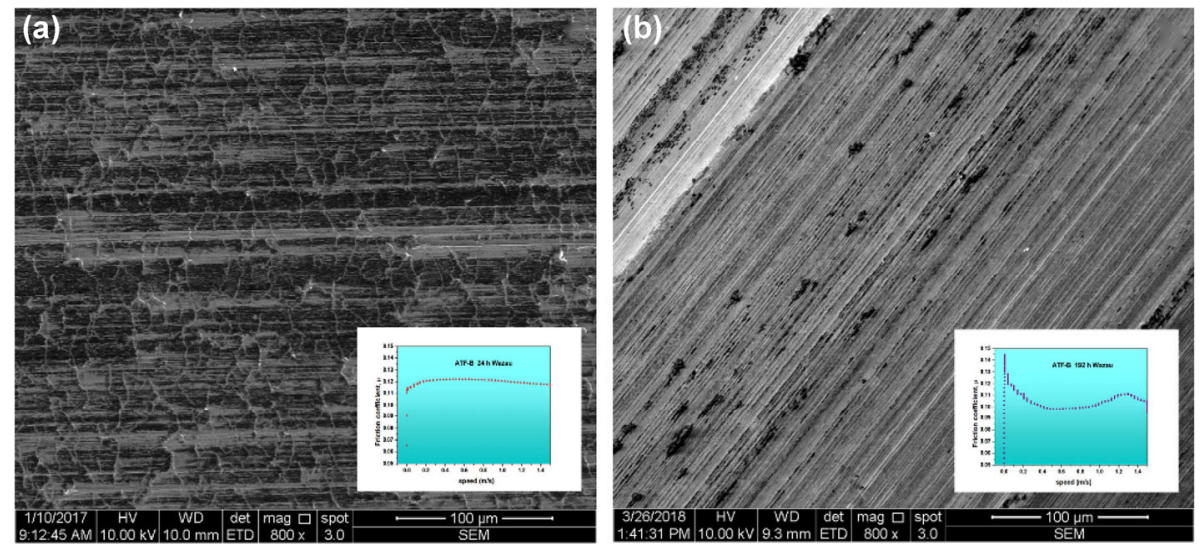

Fig. 4 SEM images of post-test steel disc surfaces after (a) $24 \mathrm{~h}$ and (b) $192 \mathrm{~h}$ Wazau durability tests for ATF-B.
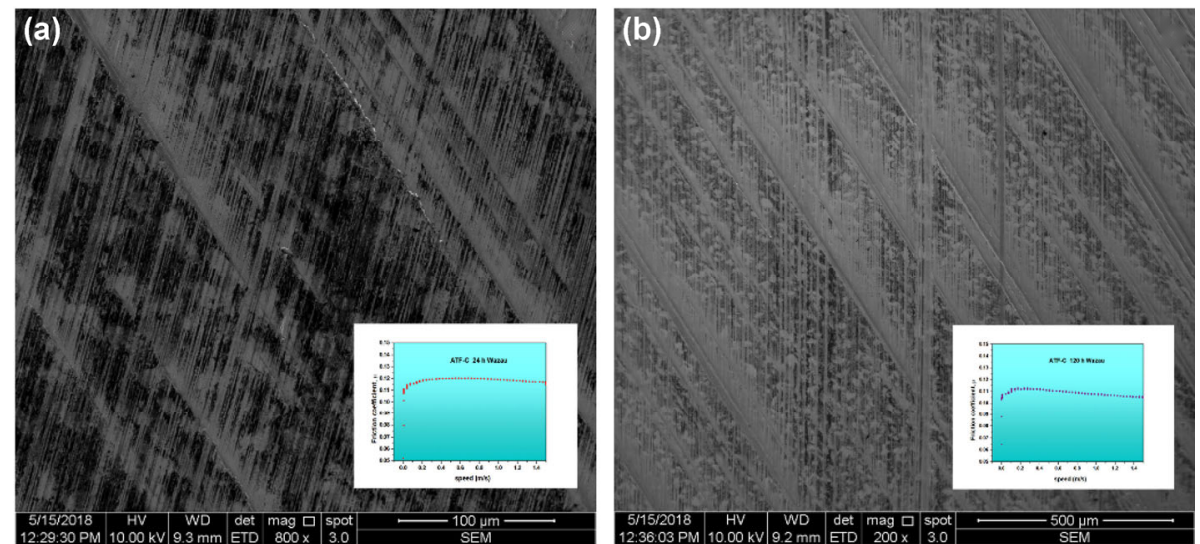

Fig. 5 SEM images of post-test steel disc surfaces after (a) $24 \mathrm{~h}$ and (b)120 h Wazau durability tests for ATF-C. 

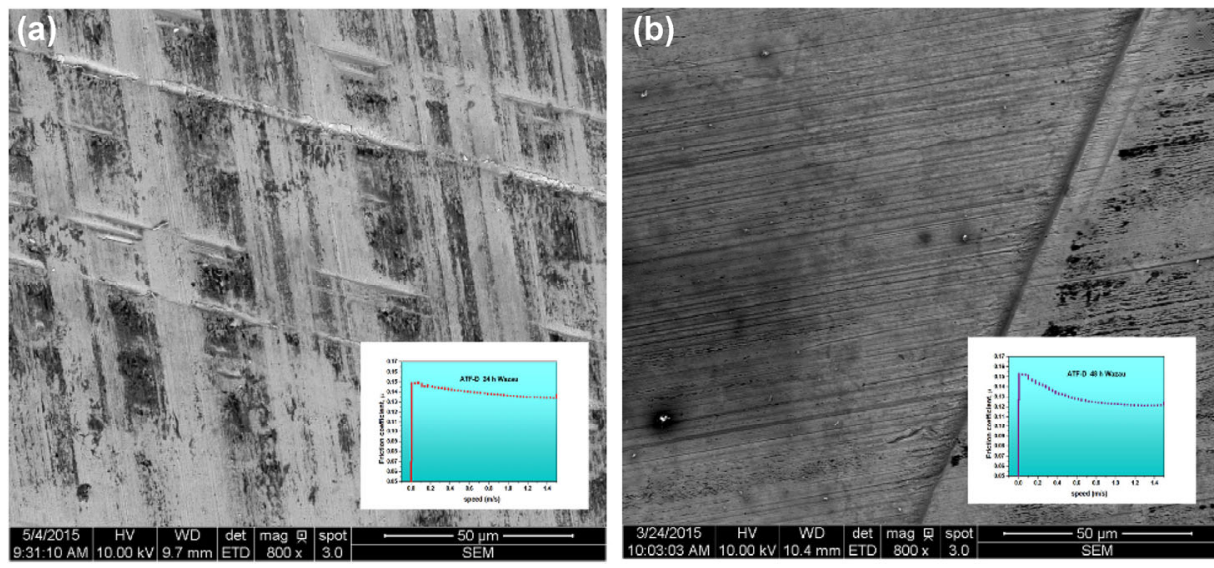

Fig. 6 SEM images of post-test steel disc surfaces after (a) $24 \mathrm{~h}$ and (b) $48 \mathrm{~h}$ Wazau durability tests for ATF-D.

(a)

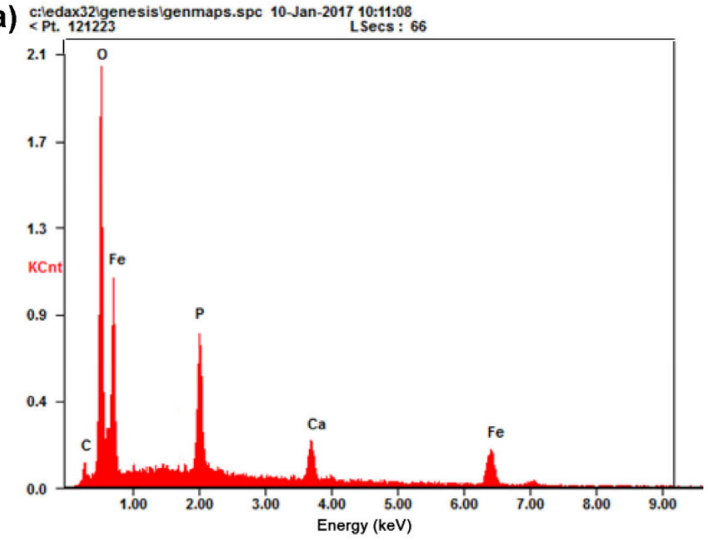

(C) Ciledax3219enesisigenmaps.spe 05-Mar-2015 10:42:43

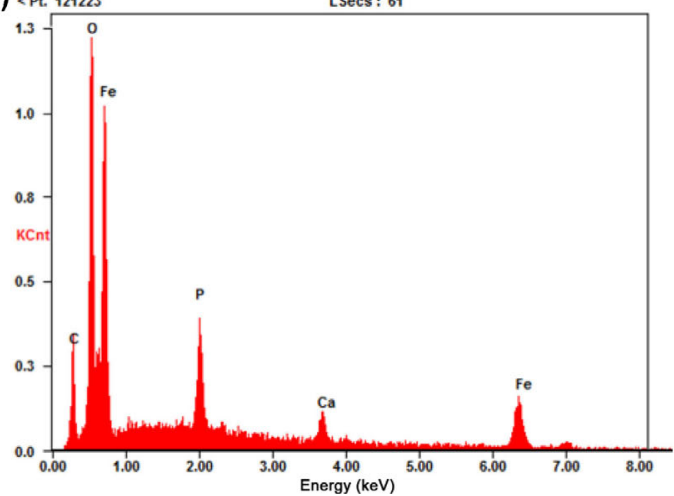

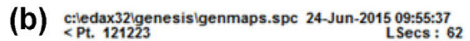

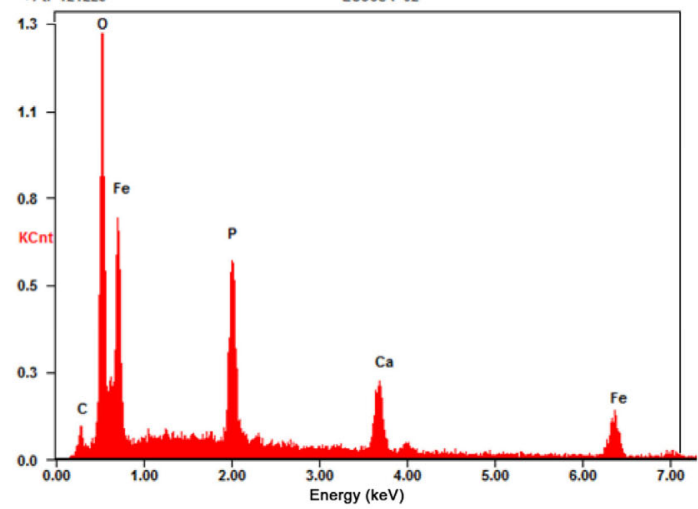

(d)

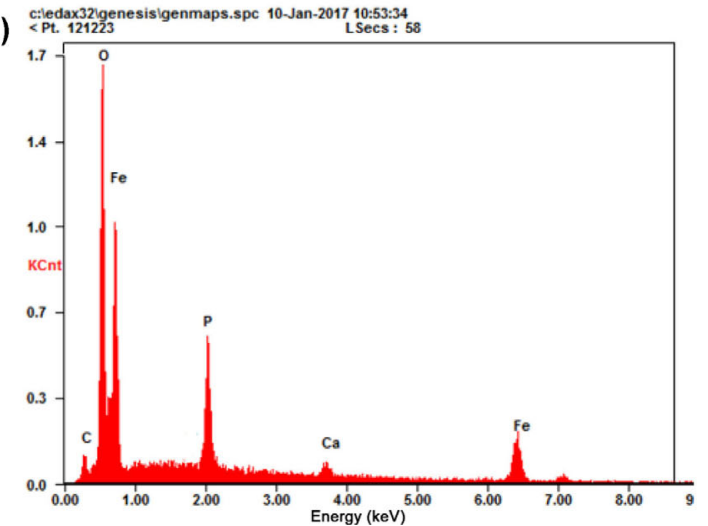

Fig. 7 EDX spectra of tribofilms on steel disc surfaces after $24 \mathrm{~h}$ Wazau durability tests: (a) ATF-A, (b) ATF-B, (c) ATF-C, and (d) ATF-D.

\section{$\mathrm{P}$, and $\mathrm{O}$.}

The $24 \mathrm{~h}$ steel surfaces of ATFs A, B, and C are distributed with bushy tribofilms, while the $24 \mathrm{~h}$ tribofilm of ATF-D is sparse (Figs. 3(a), 4(a), 5(a), and 6(a)). For ATF-A, the antishudder characteristic disappears after $72 \mathrm{~h}$ of endurance testing, and the negative slope of the $72 \mathrm{~h} \mu-v$ curve is much lower than that of the $48 \mathrm{~h} \mu-v$ curve. At the same time, the
CaP tribofilm at $72 \mathrm{~h}$ disappears (as shown in Fig. 3(b)). Similarly, at the end of ATF-B's durability test, the CaP tribofim almost disappears when the $\mu-v$ curve suddenly reaches down to the maximum negative slope value at $192 \mathrm{~h}$ (as shown in Fig. 4(b)). This phenomenon is consistent with our previous research; that is, the $\mathrm{CaP}$ tribofilm contributes to maintaining the antishudder property [19]. The slope 
of $\mu-v$ curves for ATF-C slowly decreases, and there is little difference in slope value every $24 \mathrm{~h}$. Until the antishudder characteristic disappears at $120 \mathrm{~h}$, a very sparse tribofilm remains on the steel surface (as shown in Fig. 5(b)). In the endurance-aging process of ATF-C, the slow decline of the $\mu-v$ curve slope may be related to the gradual disappearance of the CaP tribofilm.

The steel surface of ATF-D in Fig. 6 shows different features compared to the steel surfaces of the other ATFs. It has no antishudder characteristic at $0 \mathrm{~h}$, and the CaP tribofilm on the steel surface is rare. After $48 \mathrm{~h}$, the degree of negative slope deepens rapidly. The loss of antishudder is probably due to the disappearance of the CaP tribofilm.

\subsubsection{SIMS}

Figure 8 shows the $\mathrm{Ca}^{+}$2-D distribution map on the steel surface after the $24 \mathrm{~h}$ endurance test for ATFs A, $\mathrm{B}, \mathrm{C}$, and D by means of ToF-SIMS. In order to eliminate the influence of surface impurities, samples were swept by oxygen for 200 seconds before detection. The MC and TC in Fig. 8 represent the highest $\mathrm{Ca}^{+}$
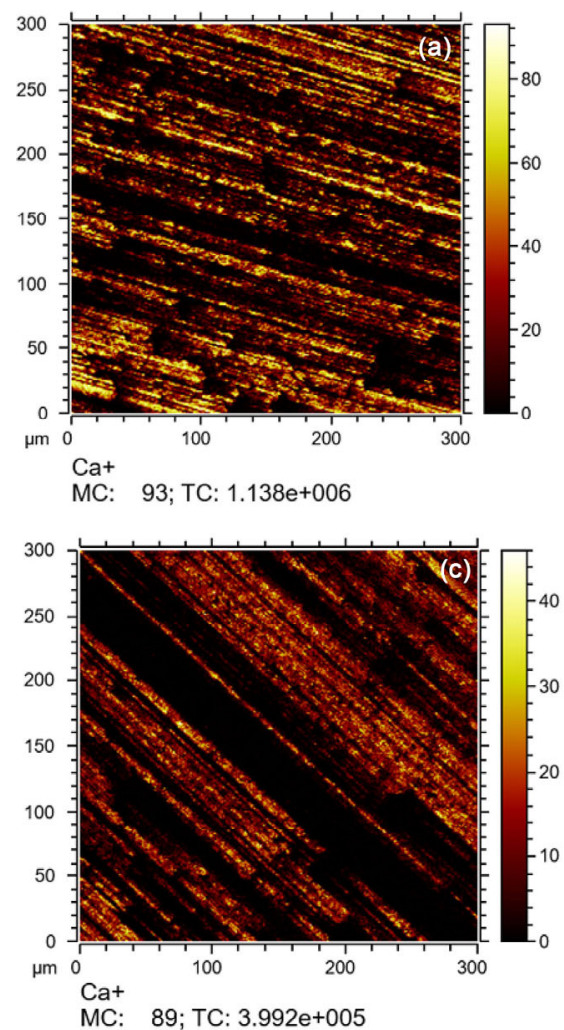

concentration in the micro detection area and the total number of $\mathrm{Ca}^{+}$in the whole detection area, respectively. In the 2-D image, the greater the brightness of yellow, the higher the concentration of $\mathrm{Ca}^{+}$in the microsphere. Therefore, the distribution of Ca for ATF-B is the most intensive and homogeneous of the four samples. The $\mathrm{Ca}^{+}$concentration in the micro detection area is $\mathrm{B}(\mathrm{MC} 116)>\mathrm{A}(\mathrm{MC} 93)>\mathrm{C}(\mathrm{MC} 89)>\mathrm{D}(\mathrm{MC} 16)$, which indicates that the thickness of the tribofilm is $\mathrm{B}>$ $\mathrm{A}>\mathrm{C}>\mathrm{D}$. From the $\mathrm{MC}$ value of A (MC 93), B (MC 116), and $C$ (MC 89), it is speculated that they have similar tribofilm thickness. This will be verified in the following XPS depth analysis. However, by comparing the total number of $\mathrm{Ca}^{+}(\mathrm{TC})$ of the four tribofilms, we conclude that the intensity of $\mathrm{Ca}^{+}$distribution of tribofilm B (TC $4.558 \mathrm{e}^{6}$ ) is much larger than that of tribofilm A (TC $1.138 \mathrm{e}^{6}$ ), C (TC $3.992 \mathrm{e}^{5}$ ), and D $\left(2.64 \mathrm{e}^{5}\right)$. These results suggest that the surface coverage of tribofilm B is greater than the others.

\subsubsection{XPS}

The XPS narrow spectra of Ca2p, P2p, and O1s regions
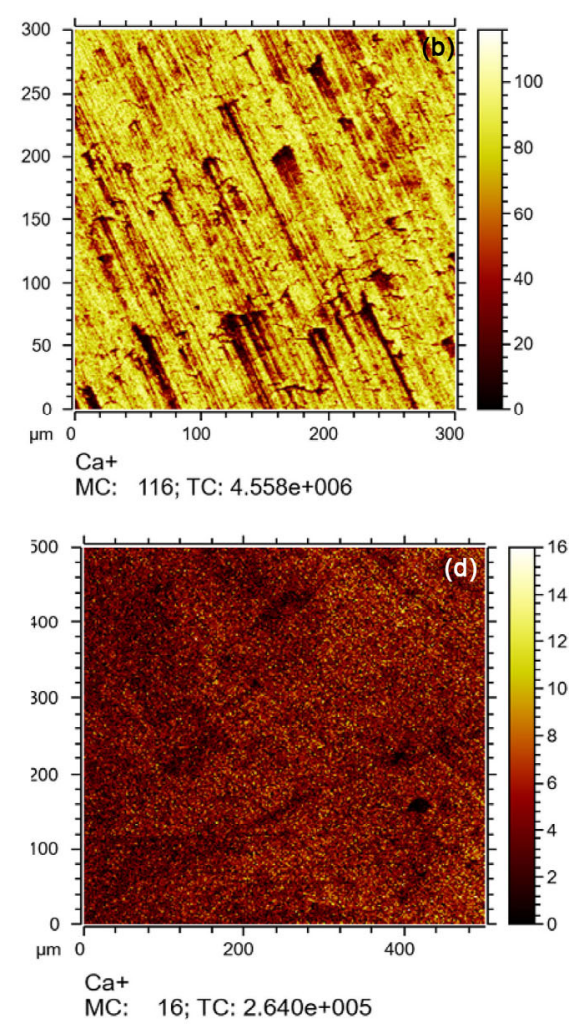

Fig. 8 ToF-SIMS mappings $(300 \mu \mathrm{m} \times 300 \mu \mathrm{m})$ of Ca for post-test $(24 \mathrm{~h}$ endurance) steel surfaces: (a) ATF-A, (b) ATF-B, (c) ATF-C, and (d) ATF-D. 
obtained from steel surfaces after the 24 h durability test for ATFs A, B, C, and D are shown in Figs. 9-12. The Ca2 $p$ and $P 2 p$ peaks detected almost match the peaks of different forms of calcium phosphate [26]. The O1s region obtained from ATFs C and D exhibit two components, indicating the presence of hydrogen phosphate groups in the tribofilms [27]. It can be inferred from these results that the components of these tribofilms are probably different forms of hydroxyapatite.
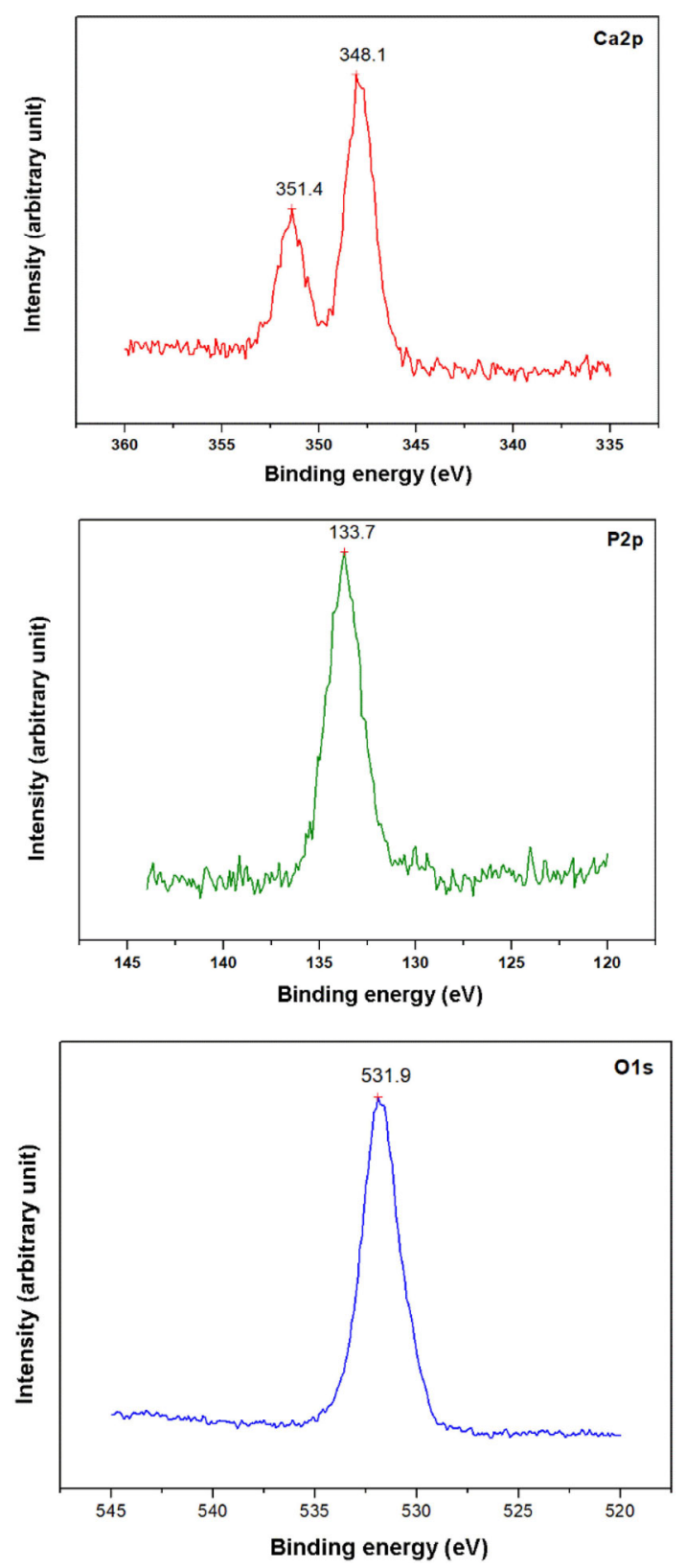

Fig. $9 \mathrm{Ca} 2 \mathrm{p}, \mathrm{P} 2 \mathrm{p}$, and O1s XPS narrow spectra of ATF-A tribofilm.
The elemental depth profiles of the tribofilms after the $24 \mathrm{~h}$ durability tests for ATFs A, B, C, and D are shown in Fig. 13 (a sputter time of $10 \mathrm{~s}$ roughly corresponds to a depth of $1 \mathrm{~nm}$ ). It is observed that the $\mathrm{P} / \mathrm{Ca}$ ratios of the three tribofilms have linear relationships (2.4:1 for ATF-A, 1:1 for ATFs B, C, and $D)$ in the depth direction. This result verifies that the tribofilms are different forms of hydroxyapatite. The tribofilm thickness of ATFs A, B, and C exceeds $900 \mathrm{~nm}$, while the thickness of ATF-D is only about
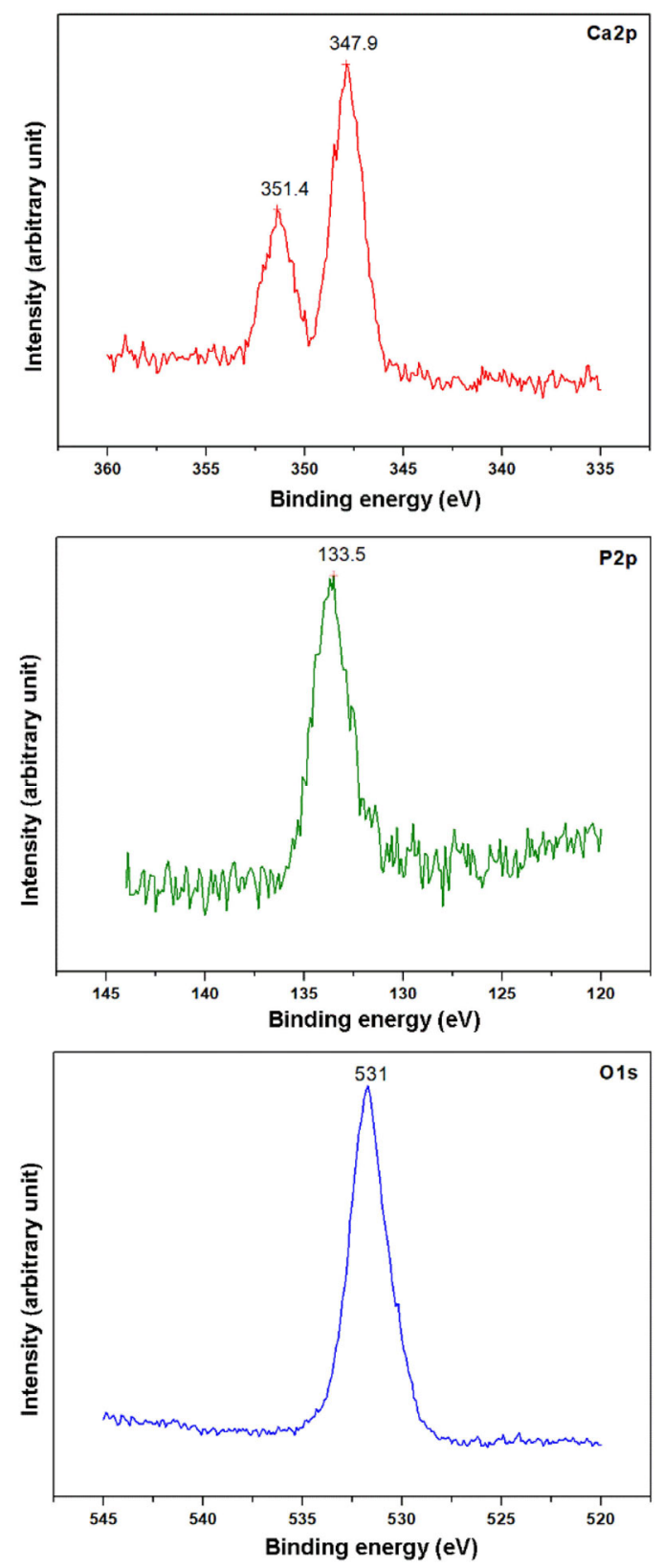

Fig. 10 Ca2p, P2p, and O1s XPS narrows pectra of ATF-B tribofilm. 

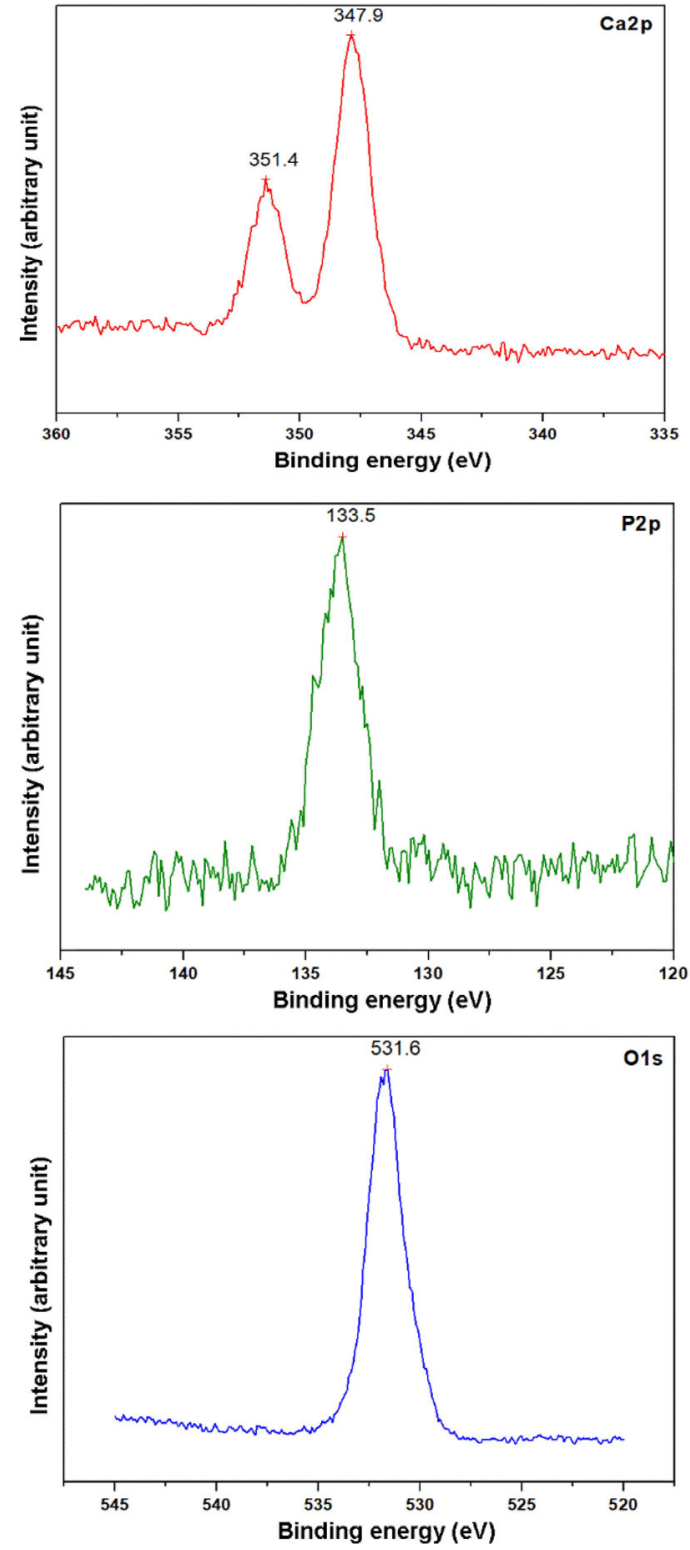

Fig. $11 \mathrm{Ca} 2 \mathrm{p}, \mathrm{P} 2 \mathrm{p}$, and O1s XPS narrow spectra of ATF-C tribofilm.

$100 \mathrm{~nm}$. At the maximum value of XPS in depth detection $(900 \mathrm{~nm})$, the percentage of $\mathrm{Fe}$ is only $50 \%$ for tribofilm B, which is less than that of tribofilms A $(80 \%)$ and $C(80 \%)$, which means the thickness of tribofilm B is larger than the others. This may explain why ATF-B has excellent antishudder property, while ATF-D does not have any antishudder ability. A hydroxyapatite tribofilm with high thickness and high coverage is helpful for maintaining good antishudder performance and durability. The tribofilm is much like a surface texture produced by the chemical reaction of additives [28].
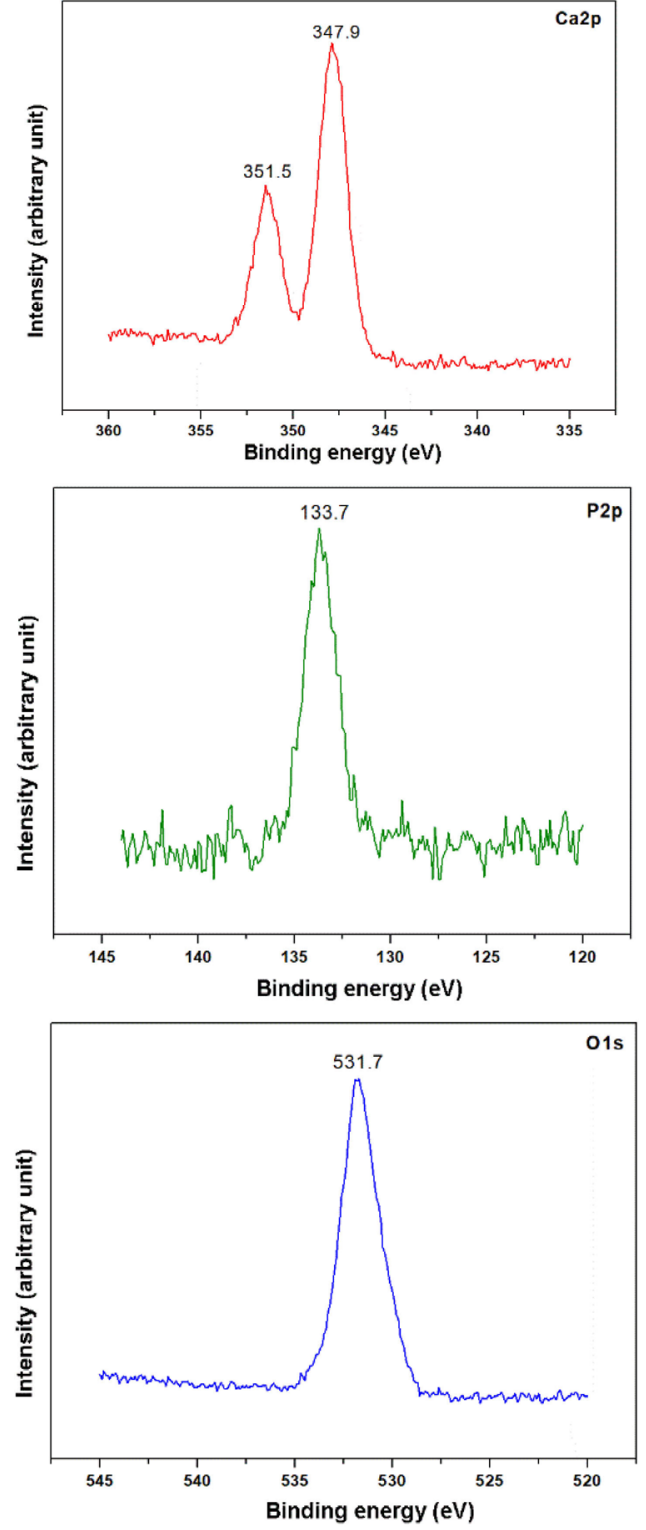

Fig. $12 \mathrm{Ca} 2 \mathrm{p}, \mathrm{P} 2 \mathrm{p}$, and O1s XPS narrow spectra of ATF-D tribofilm.

\section{Conclusions}

In this study, SEM, EDX, SIMS, and XPS analysis were used to systematically study the composition of tribofilms generated from four well-known brands of ATFs. The components of the tribofilms are all forms of hydroxyapatite. Results of XPS depth analysis and SIMS 2-D imaging show that the thickness and distribution intensity of tribofilm have a positive correlation with antishudder performance.

Among the four ATFs, ATF-B forms the thickest and highest coverage $\mathrm{CaP}$ tribofilm on the steel surface 

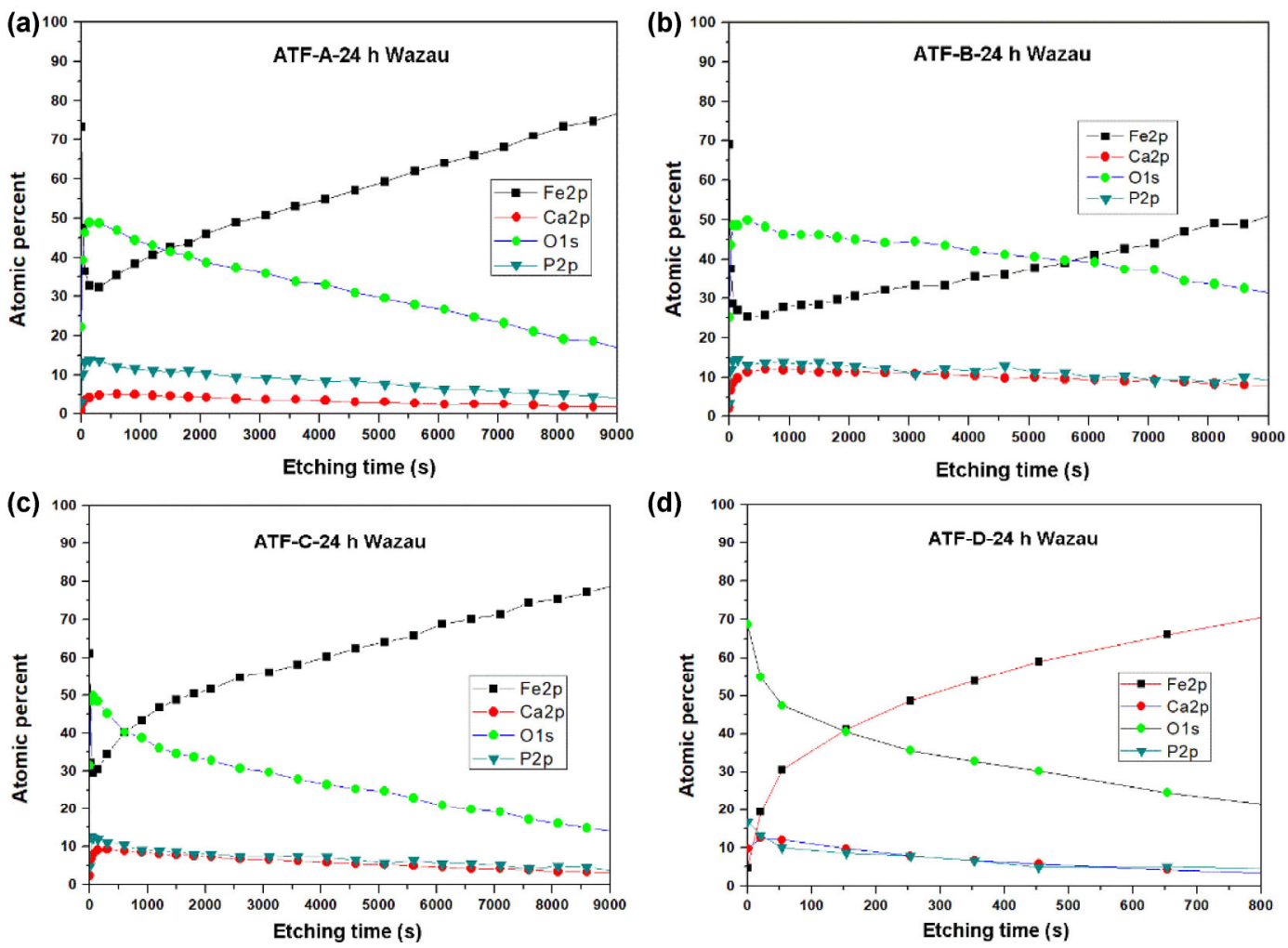

Fig. 13 XPS depth profile of the post-test ( $24 \mathrm{~h}$ durability) steel surface tribofilms for ATFs A, B, C, and D (etching rate $=0.1 \mathrm{~nm} / \mathrm{s}$ ).

with the best antishudder durability (168 h). The antishudder durability of ATF-A and C is 48 and $96 \mathrm{~h}$ respectively, probably due to their lower tribofilm coverage and depth, while ATF-D formed the thinnest $\mathrm{CaP}$ tribofilm with no antishudder property. These results suggest that $\mathrm{CaP}$ tribofilms with high thickness and high surface coverage maintain good antishudder performance and durability.

\section{Acknowledgements}

The authors are grateful to the Petrochina Company Limited for financial support.

Open Access This article is licensed under a Creative Commons Attribution 4.0 International Li-cense, which permits use, sharing, adaptation, distribution and reproduction in any medium or for-mat, as long as you give appropriate credit to the original author(s) and the source, provide a link to the Creative Commons licence, and indicate if changes were made.

The images or other third party material in this article are included in the article's Creative Commons licence, unless indicated otherwise in a credit line to the material. If material is not in-cluded in the article's Creative Commons licence and your intended use is not permitted by statutory regulation or exceeds the permitted use, you will need to obtain permission directly from the copyright holder.

To view a copy of this licence, visit http:// creativecommons.org/licenses/by/4.0/.

\section{References}

[1] Ingram M, Spikes H, Noles J, Watts R. Contact properties of a wet clutch friction material. Tribol Int 43(4): 815-821 (2010)

[2] Farfán-Cabrera L I, Gallardo-Hernández E A, Vite-Torres M, Laguna-Camacho J R. Frictional behavior of a wet clutch using blends of automatic transmission fluid (ATF) and Biolubricant (Jatropha Oil) in a pin-on-disk tester. Tribol Trans 58(5): 941-946 (2015)

[3] Xu R G, Leng Y S. Squeezing and stick-slip friction behaviors of lubricants in boundary lubrication. Proc Natl Acad Sci USA 115(26): 6560-6565 (2018)

[4] Zhang J, Meng Y G. Boundary lubrication by adsorption film. Friction 3(2): 115-147 (2015) 
[5] Parsaeian P, Ghanbarzadeh A, Van Eijk M C P, Nedelcu I, Neville A, Morina A. A new insight into the interfacial mechanisms of the tribofilm formed by zinc dialkyl dithiophosphate. Appl Surf Sci 403: 472-486 (2017)

[6] Rydel J J, Pagkalis K, Kadiric A, Rivera-Dí az-Del-Castillo P E J. The correlation between ZDDP tribofilm morphology and the microstructure of steel. Tribol Int 113: 13-25 (2017)

[7] Masuko M, Shibatsuji M, Yokomizo M, Aoki S, Suzuki A. On the effort to discriminate the principal function of tribofilm on friction under the boundary lubrication condition. Tribol Int 44(6): 702-710 (2011)

[8] Zhao H Y, Neville A, Morina A, Vickerman R, Durham J. Improved anti-shudder performance of ATFs-influence of a new friction modifier and surface chemistry. Tribol Int 46(1): 62-72 (2012)

[9] Wan Y, Kasrai M, Bancroft G M, Zhang J. Characterization of tribofilms derived from zinc dialkyldithiophosphate and salicylate detergents by X-ray absorbance near edge structure spectroscopy. Tribol Int 43(1-2): 283-288 (2010)

[10] Burkinshaw M, Neville A, Morina A, Sutton M. The lubrication of both aluminium-silicon and model silicon surfaces with calcium sulphonate and an organic antiwear additive. Tribol Int 67: 211-216 (2013)

[11] Konicek A R, Jacobs P W, Webster M N, Schilowitz A M. Role of tribofilms in wear protection. Tribol Int 94: 14-19 (2016)

[12] Stratmann A, Jacobs G, Hsu C J, Gachot C, Burghardt G. Antiwear tribofilm growth in rolling bearings under boundary lubrication conditions. Tribol Int 113: 43-49 (2017)

[13] Nicholls M A, Do T, Norton P R, Kasrai M, Bancroft G M. Review of the lubrication of metallic surfaces by zinc dialkyldithiophosphates. Tribol Int 38: 15-39 (2005)

[14] Gosvami N N, Bares J A, Mangolini F, Konicek A R, Yablon D G, Carpick R W. Mechanisms of antiwear tribofilm growth revealed in situ by single-asperity sliding contacts. Science 348(6230): 102-106 (2015)

[15] Shimizu Y, Spikes H A. The tribofilm formation of ZDDP under reciprocating pure sliding conditions. Tribol Lett 64(3): 46 (2016)

[16] Tohyama M, Ohmori T, Ueda F. Anti-shudder mechanism

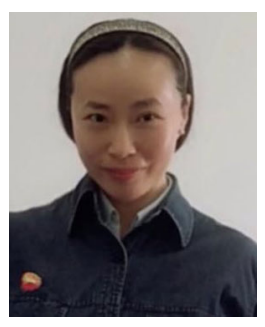

Zechao DI. She received her Ph.D. degree in mechanical engineering in 2006 from Tsinghua University, Beijng, China. She joined Lubricating of ATF additives at slip-controlled lockup clutch. SAE Technical Paper: 1999-01-3616 (1999)

[17] Derevjanik T S. Detergent and friction modifier effects on metal/metal and clutch material/metal frictional performance. SAE Technical Paper: 2001-01-1993 (2001)

[18] Fatima N, Marklund P, Larsson R. Study on the wet clutch friction interfaces for humid lubrication condition. In Proceedings of the Third International Tribology Symposium of IFToMM, Luleå, Sweden, 2013.

[19] Li S H, Di Z C, Zhao Z Y, Liu Y, Xu J J, Cui H T, Huang D S, Liu Z G, Li Y. Effection of calcium phosphate tribofilm on anti-shudder performance in ATFs. Tribol Int 120: $1-8$ (2018)

[20] Li S H, Di Z C, Cheng L, Liu Z G, Piao J C, Huang D S, Zhao Z Y, Cui H T, Li Y. Surface chemical characterization of steel clutch plate in ATF. Tribol Int 102: 319-325 (2016)

[21] Zhao H Y, Morina A, Neville A, Vickerman R. Anti-shudder properties of ATFs - investigation into tribofilm composition on clutch friction material and steel surfaces and the link to frictional performance. Tribol Trans 55(6): 782-797 (2012)

[22] Tiption C D, Huston M E, Wetsel W R. Fundamental studies on ATF friction, Part II. SAE Technical Paper: 982670 (1998)

[23] Qu J, Meyer III H M, Cai Z B, Ma C, Luo H M. Characterization of ZDDP and ionic liquid tribofilms on non-metallic coatings providing insights of tribofilm formation mechanisms. Wear 332-333: 1273-1285 (2015)

[24] Smentkowski V S, Keenan M R, Arlinghaus H. Using ToF-SIMS to study industrial surface phenomena. Surf Sci 652: 39-45 (2016)

[25] Japanese Automobile Standard JASO M349-2001 Road vehicles-Test method for anti-shudder performance of automatic transmission fluids.

[26] Boyd A R, O'Kane C, Meenan B J. Control of calcium phosphate thin film stoichiometry using multi-target sputter deposition. Surf Coat Technol 233: 131-139 (2013)

[27] Nguyen T P, Dupraz A. Spectroscopic studies of a multiphasic polymer-ceramic mixture material. J Biomater Sci Polym Ed 8(2): 141-149 (1997)

[28] Etsion I. Modeling of surface texturing in hydrodynamic lubrication. Friction 1(3): 195-209 (2013)

Oil Research \& Development Institute of PetroChina from 2007. Her research areas cover the friction and lubrication of automotive automatic transmission fluid. 